\title{
CONSIDERATIONS ON THE LIFE-HISTORY OF TAPEWORMS OF THE GENUS MONIEZIA.
}

\author{
By F. W. FLATTELY, M.Sc., \\ Lecturer in Zoology, University of Durham.
}

THE following account of observations and experiments in connection with the life-history of Moniezia tapeworms, though embodying only negative conclusions, is put forward in the hope that it may mean a certain amount of ground cleared for the benefit of other workers.

As is well known, the Moniezia tapeworms are parasitic in various species of herbivorous animals, mostly Ungulates, but are particularly common in the domestic sheep, from which they can be obtained in large numbers in the public abattoirs of any big city. Previous to 1915 a certain number of experiments had been carried out in connection with this problem but all with negative results. A few zoologists had also put forward suggestions, but these had been either insufficiently tested or had been more or less definitively shown to be incorrect.

The genus Moniezia was established by Blanchard in 1891 to include 13 species of unarmed tapeworms occurring in Bos, Ovis, Macropus, Lepus and Arctomys, and revised by Stiles in 1893. Stiles's emended diagnosis is as follows:

MonIEZIA R. Bl., 1891. Char. emend. Head without hooks, segments generally broader than long and longer than thick, end segments showing a tendency to become longer and narrower. Two full sets of genital organs, with two uteri and two lateral pores in each segment. On the right side the vagina is ventral, cirrus dorsal; on the left side vagina dorsal, cirrus ventral. Dorsal canal lies dorso-median of ventral canal. Genital canals cross the longitudinal canals and nerves dorsally. Interproglottidal glands generally present. Calcareous bodies absent from parenchyma. Eggs with well-developed pyriform body.

Stiles recognises the following species as belonging to this genus: $M$. planissima, M. Benedeni, M.Neumanni, M. expansa, M. oblongiceps, M.trigonophora, $M$. alba and $\boldsymbol{M}$. denticulata. The host species include: Domestic cattle (Bos taurus), Zebu (Bos indicus), Goat (Capra hircus), Spanish Ibex (Capra pyrenaica), Roe Deer (Cervus capreolus), Pampas Deer (Cariacus campestris), Cariacus paludosus, Cariacus nambi, Brocket (Cariacus rufus), Cariacus simplicicornis, Cariacus sp.?, Gazelle (Gazella dorcas), Musk-ox (Ovibus moschatus), Domestic Sheep (Ovis aries), Chamois or Gemse (Antilope rupicapra). 
In addition to Moniezia, Stiles recognises two related genera of tapeworms as having representatives in cattle, sheep and allied animals, viz. the genus Thysanosoma (Diesing, 1834) and Stilesia (Railliet, 1893), neither of which has so far come under my notice in Britain.

It is remarkable that notwithstanding the wide distribution of the various species of Moniezia and the commonness of their occurrence, the life-history has not in any single instance been worked out. The same is true of the other two genera of tapeworms found in herbivorous animals, viz. Thysanosoma and Stilesia. Doubtless our ignorance is to be attributed rather to lack of investigation than to anything inherently peculiar in the development of these forms, attention, naturally enough, having been focussed mainly upon the species directly affecting man or coming more closely under his notice. From an economic point of view alone, however, the life-history of Moniezia tapeworms deserves the closest attention, since the total loss to the country, owing to depreciation in the value of the lambs affected by these parasites, must be considerable.

Suggestions which have been put forward hitherto as to the life-history of Moniezia have been made from two distinct view-points. Either they require an intermediate stage in the body of some invertebrate animal or they assume that the adult tapeworm may develop directly from the egg without change of host. The first view is the one most generally held since it accords with our knowledge of the great majority of other tapeworm histories. The latter view has been supported principally by Mégnin and Curtice and, in spite of its apparent improbability, should not be hastily rejected. It has been opposed by Moniez (1879) and Railliet (1880) among others, the former, however, not altogether excluding the possibility of a direct development in the one host. Experience shows that it is rash to dogmatise about tapeworm life-histories. Grassi, for instance, in 1889, was able to infect mice with Taenia murina by feeding them on the eggs, the cysticercoid stage appearing in 3-4 days in the intestinal villi and the adult Taenia in 15-30 days. Recently a case came under my own notice of a soldier who had developed literally scores of cysticercoids of Taenia solium as a result of having accidentally ingested the eggs of this form (see Hughes, 1921). On the other hand, attempts made by Curtice, Stiles and recently by the writer to produce direct infection have all been fruitless. The thought suggests itself, however, that before finally rejecting the direct infection theory, as supported by Mégnin and Curtice, it would perhaps be advisable to determine whether some form of maturation is not necessary before the eggs will develop. In natural conditions the proglottids would hardly ever be ingested immediately they are dropped. They would probably lie about in the faeces or on the grass for some time.

Another consideration presents itself with regard to this question of direct infection, viz. the multiplicity of closely related species affecting the same host. Are we to regard this as evidence against the direct infection theory? One feels tempted to do so and to associate each particular species of Moniezia with 
a corresponding species of intermediate host: for the sake of argument, let us say, with particular species of dung beetle (Aphodius), remembering in this connection that the invertebrate host is, probably, historically the earlier and was at one time, possibly, the only host. Nevertheless, we have to bear in mind the fact that several distinct species of Strongylus, for example, which all develop directly, often occur in the same sheep and occupy precisely similar positions in the gut. We can possibly explain this fact by assuming various species of Strongylus, or of Moniezia, to have become specialised originally in connection with distinct species of wild Ungulates and to have severally adapted themselves to the sheep later on, when it came under domestication. Whether or not, then, the fact that several distinct species of Moniezia occur in the sheep affords a clue to the nature of the life-history must be left to the judgment of the individual worker.

Some experiments performed by Curtice as long ago as 1888 merit attention, but they were unfortunately too loosely controlled and indecisive to furnish reliable conclusions.

Neglecting complicating factors, we may say that Curtice was able to obtain infection among some of the lambs of a small flock under conditions such that "none of the invertebrates which are usually suggested as being the intermediary bearer were present." The most important of these conditions were as follows: accommodation, a small stable with adjoining, very dry, hill-side pasture; food, clover and grain from the market; drinking water, from an adjacent well. Curtice, however, makes no mention of ectoparasites, some species of which, in the conditions of his experiment, might well have been responsible for conveying the infection, nor of coprophagous forms; in short, there is no real ground for his claim to have disposed definitively of the idea of an intermediate host.

In 1893 Stiles reported only negative results from a series of experiments in connection with the life-history of Moniezia. These included attempts to produce direct infection by feeding eggs to sheep, and experiments to produce an intermediate stage in Melophagus ovinus, numerous coprophagous insects and earth-worms. He gave as his conclusion that some insect, worm or snail would eventually be found to contain the larval stage, and announced his intention of continuing the experiments on a larger scale. Apparently, no account of these later experiments was published.

With regard to Melophagus ovinus, this ectoparasite had already been suspected as a carrier, and examined, by McMurrich (1884), in connection with a bad outbreak of tapeworm disease (M. expansa) in Manitoba. He found nothing incriminating.

In 1915, Miss Lebour published an account of experiments she had conducted in feeding proglottids of Moniezia to the slugs Agriolimax agrestes and Arion circumscriptus. Her results were negative, the eggs, although readily ingested by the snails, failing to develop, and being recovered unchanged in the faeces. These were the last experiments previous to those of the writer. 
Among much that is doubtful in regard to the life-history of species of Moniezia one fact seems quite clear and provides a valuable hint from which the investigation of the problem may perhaps most profitably be tackled. It is the tender age at which adult, fully grown worms are found in the lamb's intestine. In America, according to Curtice (1890), individuals of Taenia (Moniezia) expansa are found measuring 2-5 yards long in lambs from 2-4 months old. This is one of the first points to which $\mathrm{I}$ directed my attention and I found that on a farm close to Aberystwyth proglottids began, in 1914, to appear in the faeces of lambs on April 10th, approximately six weeks after the lambs had been dropped. (I have since observed proglottids in the faeces of a lamb not less than four, and not more than six, weeks old.) On April 28th I observed a string of proglottids some 12 inches long in the faeces of a lamb. These showed the ovaries and yolk glands fully developed, but the uterus had not begun to spread. It is evident that for the worm to attain this condition in so short a period infection must take place either at, or very shortly after, birth. If we accept provisionally the idea of an intermediate host, then it is evident that the creature-slug, earth-worm, beetle, tick, louse, mite or what not-must be present on the pasture at lambing time, and, moreover, must be present in considerable numbers, for it is not an isolated lamb that is infected but practically all the lambs of a flock. Further, most lambs harbour not one worm but a number. In Britain, however, the variety of invertebrate life to be observed upon a pasture at lambing time, is, generally speaking, so small that if an intermediate host really does occur, the task of finding it should not be one of extraordinary difficulty.

A first visit to the above-mentioned farm near Aberystwyth was employed in examining, as an obvious preliminary step, the udders and wool of a number of ewes for parasites, but none was present. The udder region was scraped with a knife and the resulting epidermal scales, dirt, etc., were removed to the laboratory for microscopical examination. The object of this was to establish the possibility of tapeworm eggs or larval forms being transferred from the pasture to the belly of the ewe, and thence being ingested by the lamb when sucking. For, assuming that infection should occur directly from the egg, the lamb would hardly pick up the latter immediately from the pasture since in the first few weeks of its life it does little more than nose the grass in a very superficial manner.

The result of this microscopical examination was also negative. Next, grass was collected from the pasture at random, washed thoroughly, and the washings examined for possible larval forms. The result was negative. The same water was allowed to stand and was re-examined from time to time, but still without result.

On March 12th a number of specimens of the slugs Agriolimax agrestis and Arion hortensis were collected from the pasture and dissected on the chance of their furnishing an intermediate stage, particular attention being paid to the pulmonary cavity, the wall of which was cleared and examined micro- 
scopically. Result, negative. Shortly before this, as already noted, Dr Lebour had conducted experiments on feeding proglottids to various slugs and snails but had not been able to get the eggs to develop. My own conviction is that in spite of their appetite for tapeworm proglottids (see Lebour, 1915 and Grassi and Rovelli, 1892), they are very unlikely hosts for the parasite since in the last resort the lamb would require to swallow them, and this, for the reason we have seen above, it would be very unlikely to do. On the other hand, of course, it is always possible that, as noted by Miss Lebour, the eggs may undergo some alteration during their passage through the slug's intestine which, though not apparent, may influence their development in other ways. Slugs are not, however, by any means the only animals capable of rendering such a service to the tapeworm. For instance, my colleague $\mathrm{Mr} \mathrm{C}$. L. Walton and myself once derived considerable amusement from watching hens busily engaged in swallowing tapeworms lying on the floor of the Aberystwyth slaughter-house. In thinking over the various invertebrate animals capable of acting as an intermediate host, one cannot avoid being struck by the fact that while, as was already remarked, the variety of invertebrate life visible on a pasture at lambing time is very small yet one class of animals at least is exceedingly well represented, even at that early period in the year. These are the many coprophagous forms which live in sheep and cattle dung, especially Aphodius spp., small Staphylinids (Aleocharis) and mites. I have repeatedly seen species of $A$ phodius feeding in sheep dung which contained tapeworm proglottids and it seems inevitable that they should ingest tapeworm ova. It was not till some years later, however, that I was able to explore this possibility further and my conclusions concerning it are given later in this paper.

The remainder of a short research period in Aberystwyth was devoted to testing the possibility of the lamb becoming infected directly from the mother ewe, while sucking. In view of the early age at which lambs are infected it seemed not unreasonable to make the following hypothesis. Sheep when feeding ingest the ova which lie about the pasture. These ova then develop into hexacanth embryos which, in the case of the ewes, make their way, or eventually get carried, to the region of the udder. There they may develop into larval forms and remain till the ewe drops her lambs when they are passed to the lambs while sucking. The feeding process is a very energetic one on the part of the lamb and might well provide the stimulus necessary to liberate the larval Moniezia from the tissues in which it is lying into an adjacent milk duct and thence into the teats. There is nothing to prevent such a course of events provided the larva is of minute size, which it may quite well be. We may note, for instance, that Curtice and, later, Hassall, found numbers of very young forms of an unarmed tapeworm-probably Cittotaenia variabilis - in rabbits, which were less than $1 \mathrm{~mm}$. in length, one being as small as $0 \cdot 304 \mathrm{~mm}$.

Obviously, the experimental work required to test such an hypothesis $a b$ initio would need to be of a very careful kind. A short cut would be effected 
if the presence of the larval forms could be demonstrated microscopically in the udder of a ewe selected from what was known to be a regularly infected pasture. An opportunity to do this was afforded by the death of a six year old ewe at the farm under investigation. The udder was accordingly removed and a careful microscopical examination of it was made. Nothing was found in this way, which was perhaps only to be expected. Next, small snips of udder tissue were taken at various points, embedded and sectioned. For a time hopes were raised by the discovery in these sections of stages in the life-cycle of some organism or other encysted in the udder tissue. These cysts seemed more frequent in the portions of tissue taken high up the udder, in the neighbourhood of the larger branches of the lacteals and blood-vessels. They were thought to have some resemblance to hexacanth embryos. Examination under the highest powers of the microscope, however, failed to reveal any spines, which would definitely determine their character. What under the lower powers seemed to resemble spines turned out to be tears or folds in an internal membrane. I now hold the view that these are stages in the life-history of some Protozoan parasite.

In pursuance of the same idea a quantity of milk from the ewes on this farm was examined microscopically, but failed to give anything of interest. This is obviously a very slow process and various methods of speeding it up were tried: evaporating, centrifuging, etc., but always without result. It was of considerable interest to notice that the small intestine of the old ewe already mentioned contained several tapeworms all of which were in a very ill-nourished condition, quite unlike those occurring in young lambs. How long the ewe had harboured these worms it is, of course, impossible to say. It is well known that infection with tapeworm only reaches serious proportions in young lambs: shepherds will say that they hardly ever notice proglottids in the faeces of older sheep and, similarly, butchers hardly remark the presence of worms in older sheep slaughtered at the abattoirs. Had these emaciated-looking worms hung on from the early period of the ewe's life or were they acquired subsequently? From the point of view of the life-history it is of capital importance to establish whether infection is contracted only in the period before the lamb is weaned or continuously all through life. If the latter is the case then it would effectually dispose of the idea that the lamb acquires infection through its mother, and the fact that the worms are so much less often observed in older sheep would simply mean that the conditions for the development of the tapeworm are then less favourable, owing to the substitution of an herbivorous diet for one of milk. Speaking of the occurrence of M. expansa in the United States, Cooper Curtice (1890) says that

the worm, though present throughout the year, is more abundant in the locality of Washington during May and June than at any other season....In Colorado an outbreak was heard of in a flock of Merinos which occurred annually about July and August, after which the lambs would improve. The disease is more prevalent in the summer season, and causes the greatest damage in lambs less than six months old. If the young animals can be carried beyond this age they seem to be either better able to withstand the ravages of the parasite, or 
to have reached a season unfavourable for its development... The broad tapeworms do not last long in their adult state but after maturing all their segments are shed at once. From the time that the segments are shed the afflicted lambs will begin to receive and rapidly lay on fat.

The above remarks of Curtice's on the occurrence of Moniezia in the States describe exactly the conditions prevailing with regard to the disease in this country, and the recrudescence of the trouble yearly in early summer goes some way towards supporting the view that the lambs are infected only at, or soon after, birth, and do not become re-infected later. It may also mean, of course, simply that the conditions for the development of the parasite in the older sheep are less favourable. The writer does not altogether agree with Curtice's statement that the worms are at once shed after maturing all their segments, but inclines to the view that in many cases the scolex will hang on for a considerable period and make an attempt at maturing fresh segments.

On the whole, investigations at Aberystwyth left the writer without any particular conviction as to what lines future research should follow, but with the feeling that two hypotheses merited careful testing. They were (1) that infection may be conveyed from the mother to the lamb when sucking, the intermediate stage being assumed to be present in the ewe's udder; in other words that intermediate and adult stages occur in different parts of the same host, and (2) that infection may be conveyed through the intermediary of some coprophagous mite or beetle which is picked up by the lamb, directly, when nosing the grass or, indirectly, from the fleece of the mother-ewe when the lamb is sucking.

The following notes were made on the occurrence of tapeworms in lambs approximately three months old from the Aberystwyth slaughter-house, and serve to illustrate what has been remarked above regarding the early age at which lambs become infected, and also to indicate that the whole of the infection does not take place simultaneously but that re-infection occurs at intervals.

June 9th, 1915. "String" of lamb from slaughter-house. Five individual tapeworms were found. The specimens varied considerably in size and degree of maturity. In one case the proglottids reached a size of $11 \mathrm{~mm}$. and mature ova were present in segments situated approximately $120 \mathrm{~mm}$. behind the scolex, the number of segments in this length being roughly 530. The remainder showed no ova at $275 \mathrm{~mm}$. behind the scolex, in which length there was approximately the same number (530) of segments, the latter being a little over twice as long as in the previous case.

Same date. String of lamb from slaughter-house. Two worms, one with fully mature proglottids, broad and extremely short, the other with appreciably longer proglottids and no mature ova.

June 11th. String of lamb supplied by local butcher. Seven individual worms. There is a considerable difference in appearance among the worms of 
this batch. In some the "neck" is extremely long and thin, and it is only beyond a distance of several inches that the proglottids begin widening out. In others the neck is very short and the proglottids rapidly become very broad.

June 12th. In the string of a single lamb from the slaughter-house on this date, I found 75 individuals, the aggregate length of which was 150 feet. The worms showed the same differences in appearance as those in the preceding batch. There is no doubt about the extraordinary degree of infection in this case, as 75 was the number of scolices found. Curtice states that the number of individuals occurring in the same intestine may be from two or three to a hundred, but that it is unusual to find more than half a dozen adults together. He himself observed as many as $\mathbf{1 4}$ adult worms in a lamb four months old.

According to observations made at the time, the above worms belonged to one or other of two species, viz. M. expansa and M. trigonophora, the former being much the more numerous. If my identification of the latter species is correct then the two species occurred together in the same lamb. The identification was based on microscopic characters and not on externals which, as Stiles has pointed out, vary tremendously according to the age of the worm and the state of contraction. Thus, $M$. expansa may show precisely the differences which have been above noted, viz. in some individuals the neck may be extremely long and thin, the proglottids widening out very gradually, while in others the neck is very short and the proglottids become quite broad only a short distance behind the scolex. The characters which led me to identify some of the individuals as $M$. trigonophora were mainly (1) the presence of interproglottidal glands grouped around blind sacs, and (2) the arrangement of the testicles in two triangles, one at each side of the segment. I am anxious, however, not to attach too much importance to the occurrence of M. trigonophora in Wales, since I have not since found it elsewhere, and since also the triangular arrangement of the testicles is not absolutely decisive, $M$. expansa itself occasionally showing the same arrangement in certain segments.

In addition to the specimens above noted which were obtained by myself from the Aberystwyth abattoirs, I was later able to examine a large batch procured for me from the same source through the kindness of Mr T. A. Stephenson, M.Sc. These proved without exception to be specimens of $M$. expansa. A few notes on these are appended. In Nov. 1919, I further received from Mr C. L. Walton, M.Sc., a strobila from a lamb in all probability reared in Carnarvonshire and grazed in Anglesea. From the shape of the proglottids (longer and narrower than those of $M$. expansa), position of the genital pores, absence of interproglottidal glands and, finally, the character of the scolex, I have no hesitation in putting this specimen down as $M$. alba. 


\section{OBSERVATIONS ON THE OCCURRENCE OF MONIEZIA IN THE ROMAN CAMPAGNA.}

When in Rome I was able to make a few observations on the occurrence of tapeworm in this area which may prove of interest. At the outset $I$ was inclined to think that the disease would be of relatively rare occurrence on the wide and rough pastures in the neighbourhood of Rome. The contrary proved to be the case.

So far as my inquiries went there was relatively little infection on the mountain pastures and sheep walks in Wales, and the explanation of this $I$ took to be that the rough nature of the pasture and the wide area over which the sheep roam would mean that the eggs were less likely to be encountered by a fresh host. The same argument might reasonably be considered applicable to the Roman Campagna. The following fact, however, destroys the analogy. The flocks in the Campagna are large (two or three hundred head or more) and though they pasture over large areas under the care of a shepherd, they are regularly rounded-up at night and closely folded until well on in the following morning. In order to discover whether infection exists it is only necessary to visit the spots where the animals have spent the night and where quantities of faeces have collected. Except in one or two cases, lambs of two, three and four months old were always found to be infected. There is thus ample scope for infection, either directly, or by means of an intermediate host. Even if infection does not occur at the time (owing, say, to the period of the flock's stay being too short to allow of infection by means of an intermediate host), nevertheless these areas, being literally saturated with eggs, may well serve as centres of infection which the sheep will be almost bound sooner or later to cross again.

The same ideas regarding the conditions of infection prevail as in England, viz. there is a marked tendency to associate it with wet pastures. I have always tried to resist an undue bias in this direction since the judgment seems to be based on the general tendency to connect all ailments, human and otherwise, with damp situations and is not the result of observation. There was no difficulty in obtaining evidence of infection from wet localities, but I had great trouble in persuading the laboratory attendant who was helping me to accompany me to a portion of the Campagna which could be regarded as really dry. On our first visit to such a district we found a large flock of lambs about four months old to be infected. Unfortunately, it is extremely hazardous to draw any conclusions from this fact as the flocks in the Campagna are continually being moved about, so that the spot at which one finds evidence of infection at any particular moment may be at a considerable distance from the one where infection was contracted. Lambing in the Campagna takes place as soon as the sheep return from the hills, i.e. September, and continues until January and to a certain extent until February. It was, unfortunately, quite impossible to get the history of any one flock and to keep in touch with it, 
as was imperative if any definite conclusion was to be drawn as to the conditions favouring infection.

Lambs are slaughtered for the market at a very tender age around Rome -at two to three weeks old, in fact. Advantage of this was taken to endeavour to fix how soon after birth it was possible to get direct evidence of infection. A most careful examination was made with a lens of a number of intestines of lambs a fortnight old but failed to reveal any scolices. I was therefore forced to conclude that infection had not yet occurred. Curtice took some very small individuals about $2 \mathrm{~mm}$. long (which he figures) from a lamb, but does not state the latter's age. The point is not perhaps of fundamental importance for, as we have already seen, we are bound to infer that infection takes place at a very early stage.

A point worth mentioning is that I learned from the Roman abattoirs that whereas lambs from the Campagna Romana and Sardinia are regularly infected with tapeworm, those from the Marches of Ancona, from Romagna (Ravenna), Perugia and Umbria, where the sheep are stable reared, are free from infection. How far this statement can be relied on it is difficult to say. Dr Zürn, on the other hand (1882), states that the disease also occurs among sheep which have been fed entirely in the stalls, but more especially among the younger and youngest of a flock which are put to graze.

\section{OBSERVATIONS ON MONIEZIA IN THE ABERDEEN AREA.}

There are very few flocks in the country immediately round Aberdeen and none of which any history of infection could be procured. Through the kind offices of Mr W. Brown, M.R.C.V.S., Lecturer in Veterinary Science at the University, I was able to get in touch with a farm in Forfarshire where a certain anount of infection was known to occur with fair regularity. I visited the farm in March, 1919, when lambing was well begun and examined the fleece of a number of ewes for ectoparasites, paying particular attention to the belly region, but found no signs of any parasites: keds, lice, etc. whatever. A closer scrutiny of a quantity of wool which was removed to the laboratory also proved fruitless. The farmer himself was confident that none would be found, his being pedigree sheep living under ideal conditions. It is a distinet disadvantage in connection with this research that while one is compelled to look for the agent of infection in February-March, it is not till three months later that one gets to know whether infection has actually been heavy, light, or absent. This is one reason why it is essential to conduct one's researches on a farm where infection is not sporadic but is known to occur regularly year after year. This notwithstanding, one may go so far as to say that here was a farm where ectoparasites would probably be at a minimum and which nevertheless had a fairly regular history of infection. The fact seems significant.

There seems to be only one plausible reason why infection occurred fairly regularly on this particular farm, viz. the fact that lambing was always carried out in the same meadow, which was therefore likely to be heavily infected with 
eggs passed by the ewes. A number of invertebrates were collected from this meadow: Aphodius punctato-sulcatus, A. ater, Aleocharis, dung-flies (Scatophaga stercoraria), earth-worms (Lumbricus terrestris), and carefully dissected in the laboratory (the earth-worms were sectioned), but without result.

During the spring of 1919 and again in the spring of 1920 it was determined to test the possibility of dung beetles acting as carriers more thoroughly. From the farm above discussed, and from another in the same neighbourhood which also had a history of infection, over a hundred individuals of Aphodius (various species, mostly $A$. punctato-sulcatus, but also $A$. prodromus, $A$. ater and $A$. rufipes, about three-score Staphylinids (Aleocharis lanuginosa), a score of dung-flies (S. stercoraria) were collected and dissected, all without result.

The following experiment was also performed:

A number of dung beetles, mainly $A$. punctato-sulcatus, were kept among sheep faeces liberally sprinkled with tapeworm ova, for a period of several weeks. The faeces were spread upon turf in the open and covered by a rectangular frame $18^{\prime \prime} \times 18^{\prime \prime} \times 5^{\prime \prime}$ with a top of narrow-meshed wire gauze, the sides of the frame being sunk a couple of inches into the grass. Under natural conditions, the beetles do not occur either in perfectly fresh or in comparatively stale dung since they require time in order to locate and enter the dung, and vacate it when it begins to dry up. Consequently it was necessary to remove the stale dung periodically and to substitute fresh dung which was also, of course, sprinkled with eggs. At the end of three weeks most of the beetles still present were removed and dissected under the microscope. Occasional eggs were detected in the gut of some of the beetles, but nothing in the nature of an intermediate stage was found. A few further beetles were collected from the faeces subsequently but they too gave negative results. Altogether some 20 beetles were dealt with in this way. This was only a small fraction of the beetles originally present in the faeces, a number having died or escaped.

Another set of observations in Aberdeen was directed towards ascertaining the effect of long exposure to weather upon the eggs of Moniezia. Short series of proglottids were scattered upon a medium of $(a)$ pure, washed sand, and (b) garden soil contained in seedling boxes, and exposed to the weather from early October till shortly before Christmas. The boxes were covered with perforated zine through which the rain had free access; they had the usual arrangements for drainage but were lined at sides and bottom with a double layer of the finest bolting cloth to prevent the eggs from being washed away. A further lot of isolated proglottids were placed in a jar full of tap-water (c) covered with fine bolting cloth which was left in the open under the same conditions as the boxes.

Notwithstanding that the season was a fairly wet one the proglottids in both boxes $(a)$ and $(b)$, when examined after nearly three months were distinctly desiccated. They had not so much decomposed as shrunk to a thin film. The effects were more marked in the case of those which were lying on sand. The eggs recovered from these proglottids by teasing in water were in the case 
of $(a)$ burst practically without exception. In the case of $(b)$ the eggs remaining apparently intact were slightly more numerous. Very strikingly different was the case of the eggs kept in water: these seemed to have increased slightly in size, were perfectly regular in shape, their envelope intact and, in short, appeared all ready for development except that there was no movement to be detected within the egg. Judging by appearances, therefore, the viability of the egg seems to be distinctly favoured by the presence of water. This conclusion is not new of course (see Ministry of Agriculture Leaflet, No. 119), but it is interesting to have obtained experimental evidence in a matter which is of considerable practical importance. It does not necessarily follow from this that the presence of water is essential to the life-history (although it may be so); if the intermediate host should be a member of the dung fauna then the eggs will either be ingested within a comparatively short period (say a week), or will have lost their opportunity definitively, in which case their subsequent viability is not of much moment.

A considerable number of worms were collected from the Aberdeen abattoirs at various times and proved to be $M$. expansa. without exception.

\section{OBSERVATIONS ON MONIEZIA IN THE NEWCASTLE-ON-TYNE AREA.}

Through the courtesy of Prof. Gilchrist and the members of the Northumberland Education Committee, I was able to carry out a feeding experiment to test the possibility of a sheep acting both as intermediate and as final host to the worm. I thought it possible that by feeding eggs to a ewe, larval stages (hexacanths, cysticercoids or what not) might be recovered later from the tissues, notably the udder region. If this should prove to be the case then it would not be difficult to round off the life-cycle by supposing the embryo to remain dormant in the udder region of the ewe until it had dropped its lambs, when the embryos would be passed to the offspring when sucking. The arguments for and against such a theory were discussed eárlier in this paper. The feeding experiment was actually performed upon a Sussex half-bred ewelamb only a week old. It would have been more logical to select an older sheep but this was not found practicable; moreover, by selecting a newly-born lamb the experiment would serve at the same time to demonstrate the possibility or not of direct infection. Again, it seems not unlikely that a lamb would pick up eggs from the pastures at an early date under natural conditions, though possibly not until after it had begun to graze in earnest.

A quantity of eggs were isolated from ripe proglottids and administered in 50 c.c. of water to the lamb on Thursday, April 14th, 1921, with the aid of a small syringe, being squirted over the tongue and sides of the mouth. Care was taken to use eggs from as many different individual tapeworms as possible and from proglottids which had all the appearance of being properly mature. The dose was repeated a fortnight later. After being dosed, the lamb was put back with the mother-ewe and allowed the same liberty as the rest of the flock. No control lamb was used and the fact that the experimental lamb was 
allowed complete liberty also complicated the experiment. The reason for not adopting a control was simply that of expense. The chances of success were so doubtful that the sacrifice of more than one lamb seemed unwarranted. The present experiment was intended as a "sighting shot" merely; if it were to furnish a clue it could be repeated the following season under the strictest control.

On August 9th, that is to say, nearly four months after the administration of the first dose, the lamb was slaughtered and the udder region and also the alimentary canal were taken away for examination. Microscopic examination showed nothing out of the ordinary, the lamb was fat and had thriven well; there were no signs of adult tapeworms in the gut. A number of preparations were made of the udder and small intestine and were carefully examined, but no larval stage was found. The result of the experiment was therefore negative, both as regards the possibility of direct infection and in respect of an intermediate stage in the same host as the adult worm.

As already noted, it is of critical importance in connection with this supposed mode of infection through the intermediary of the ewe, to establish whether Moniezia infection may be contracted by the lambs after they have been weaned. If this is really proved to be the case, then the above experiment loses most of its raison d'être, unless there is a dual method of infection, which seems most unlikely. I am not satisfied, however, that infection with species of Moniezia does occur after the lamb has been weaned. Certainly, I have neither obtained myself nor read any conclusive evidence on this point.

All the worms collected from Newcastle sources belonged to the one species, $M$. expansa.

\section{SUMMARY.}

Lambs contract Moniezia infection either at or very soon after birth, since they have been observed to harbour adult worms at 2-3 months old and in one case, to pass proglottids at $4-6$ weeks.

The intermediate host, if such exists, must be frequent on the pasture in early spring, otherwise lambs would not be found to harbour adult tapeworms so regularly or in such numbers when slaughtered in early summer. In the small intestine of a lamb from 3-4 months old slaughtered at Aberystwyth, there occurred 75 individuals.

The fact that lambs regularly harbour adult tapeworms before they are weaned suggests the possibility of their contracting the infection from the mother-ewes. No direct evidence in this direction has been obtained, however, and an attempt to produce a larval stage in the udder region of a ewe by feeding to it the eggs of a tapeworm proved abortive.

Hitherto, all attempts to produce the adult tapeworms directly by feeding the eggs to sheep have failed; there is, however, the remote possibility that the eggs require to undergo some kind of maturation process outside the body of the sheep before they will develop. The fact that several species of Moniezia occur in the domestic sheep would seem to require an intermediate stage, which would occur in a corresponding number of intermediate-host species. 
The disease seems prevalent in flocks which are singularly free from ectoparasites.

The invertebrates which seem most likely to harbour an intermediate stage are coprophagous insects, etc. (beetles, flies, mites). Attempts to infect species of Aphodius have nevertheless proved fruitless.

Moisture favours the survival of the eggs of Moniezia: eggs kept in water for a period of several months seemed to remain perfectly viable. Nevertheless tapeworm is common among flocks on pastures about Rome which are characteristically dry.

A comprehensive series of experiments under conditions of the most complete control would almost certainly clear up the life-history; on economic grounds alone the problem is urgent.

The overwhelming majority of a quantity of worms collected from slaughterhouses in Aberystwyth, Aberdeen, Beauly (Inverness-shire) and Newcastleon-Tyne proved to be of the species $M$. expansa. The only other species found were $M$. trigonophora and $M$. alba. The identification was based on anatomical characters and not on externals, which are useless.

The writer intends directing his attention to coprophagous mites as carriers, viz. Gamasus coleoptratorum, G. fimetorum, Macrocheles glaber.

\section{BIBLIOGRAPHY.}

Bradn, M. (1894-1900). In Bronn's Klassen und Ordnungen des Thier-Reiches. Iv.Abt. I. b. Cestodes. Leipzig.

Blanchard, R. (1891). Notices helminthologiques, $2^{\mathrm{e}}$ ser. Mém. de la Soc. Zool. de France, Iv. Paris.

Curtice, Cooper (1890). The Animal Parasites of Sheep. U.S. Dept of Agric. Bureau of Animal Industry. Washington.

Diesina, C. (1834). Medic. Jahrb. d. K. K. Öster, Staates, xxvi. N.F. Bd vi.

Flattely, F. W. (iv. 1920). Scottish Journ. of Agric. III. No. 2.

Grassi, J. B. and Rovelut, G. (1889). Embryologische Forschungen an Cestoden. Centralbl. f. Bacteriol. Parasitenk. Bd v.

- (1892). Ricerche embriologiche sui Cestodi. Atti Accad. Gioenia di sc. nat. in Catania, Iv. ser. 4.

Harrison, L. (18. xi. 1915). Nature, xcvr. No. 2403.

Hughes, J. R. A. (5. x. 1922). Case of Cysticercus cellulosae in man. Lancet.

Lebour, M. V. (i. 1915). Some Feeding Habits of Slugs. Ann. Applied Biol. I. Nos. 3 and 4.

McMurrich, J. P. (1884). Ninth Ann. Rept. Ontario, Agric. Coll. Toronto.

Mécnin, J. P. (1883). Sur la reproduction directe des Ténias. C. R. Acad. des Sci. Paris.

Moniez, R. (1879). Bull. Sci. du depart. du Nord. $2^{\mathrm{e}}$ ser. $2^{\mathrm{e}}$ ann.

Railliet, A. (1880). Recherches sur le développement et les metamorphoses des ténias incrmes des herbivores. Arch. Vétérin. publ. à l'école d'Alfort, v.

Rrehm, G. (1881). Studien au Cestoden. Zeitschr. f. d. ges. Naturwiss, LIv. Halle.

Stiles, C. W. and Hassali, A. (1893). A Revision of the Adult Cestodes of Cattle, Sheep and Allied Animals. Bureau of Animal Industry, Bull. No. 4.

Stiles, C. W. (1897). A Revision of the Adult Tapeworms of Hares and Rabbits. Proc. U.S Nat. Museum, xIx. No. 1105.

Villot, A. (1883). Mémoire sur les Cysticerques des Ténias. Ann. Sci. Nat. Zool. xv.

ZÜRN, F. A. (1882). Die Schmarotzer unserer Haussäugethiere. Weimar. 